\begin{tabular}{l|l} 
Cognitive Science - & Vol. 5 \\
New Media - Education & {$[2 / 2018]$}
\end{tabular}

DOI: http://dx.doi.org/10.12775/CSNME.2018.010

Received: December, 2018 / Accepted: a) January 12, 2019; b) September 9, 2019

\title{
Roald Larsen
}

UiT The Artic University of Norway

e-mail: roald.larsen@uit.no

\section{The reception of North-Norwegian Magazine (NNM) in the daily press - response and counter-response}

\begin{abstract}
This article has as its purpose to look closer at the the reception of the northern journal, NNM in the daily press during the first decade of the magazine's existence, in the period of 1978-1987. I will have a look at how the magazine has been taken by daily press and how the journal is regarding this response. The reason for this period is first of all that the magazine at this time was Norway's largest culture magazine, and it is remarkable because the northern part of Norway has relatively few inhabitants compared to the southern part of the country. Through its high circulation the periodical's influence was large and was in many ways a reflection of thoughts and activities which were of importance in many aspects of cultural life in Northern Norway during that decade. As a professor at an arctic university, this journal has been an important setting for my research and lecture on northern literature and literature didactics.
\end{abstract}

Keywords: newspapers, readers' letters, reception, cultural periodical, magazine, Northern Norway

\section{Introduction}

NNM is a cultural periodical which is published in Northern Norway and has existed since 1978 (Larsen, 2012). The purpose of this article is to take a closer look at the reception of NNM in the daily press during the first decade of the magazine's existence, in the period of 1978-1987. 
I will have a look at how the magazine has been taken by daily press. During this time period this magazine was the largest cultural periodical in Norway taking into consideration circulation, which is remarkable since the northern part of Norway is sparsely populated. Hans Kristian Eriksen, the editor of the journal, was happy with the state of things, but says in his editorials in particular that many people thought that NNM was a stillborn initiative when it was started. The editor claims also that NNM has been criticized, stigmatized and tried to be concealed, especially by some circles hoping that the magazine would be stopped as soon as possible (Larsen, 2017). I will look into these claims and comment on them.

\section{Readers' letters ${ }^{1}$}

Hans Kristian Eriksen wrote in several editorials about the reception of NNM. Already after the first issue the magazine got several hundred letters from the satisfied readers who bade the magazine welcome (Eriksen, 1978, p. 3). In the editorial of 1980 (Eriksen, 1980a, p. 3) Eriksen wrote that delight utterances concerning the existence of Magazine streamed in constantly, almost delightful utterances only.

Eriksen said that he and the rest of the editorial staff were grateful for this. These warm greetings result in getting the necessary surplus by the editorial staff in order to continue publishing the magazine and also to improve the product. Eriksen said to Class Struggle (1980) that the editorial staff had a feeling that many readers understood the course which the magazine had been and was following.

A small minority of readers were not much satisfied. Accordng to the editorial of 1979 (Eriksen, 1979a, p. 3) some letters of this kind were received. The critical voices claimed in particular that NNM had a too narrow choice of topics. The magazine wrote about and gave most space

\footnotetext{
1 A possible source of error here is that I had to build on the editor's statements concerning some criticism raised against NNM. It applies to letters received by the editorial staff. I haven't read these letters. The only thing I know about their contents is Eriksen's general comments on them in editorials of NNM. In this case I can neither disprove nor confi rm these statements which editor express as regard to these letters. Probably there haven't been many critical voices which have resulted in readers' letters. The editor writes in the editorial (NNM, issue $4 / 79,3$.) that there were few negative readers' letters received by NNM compared to such utterances in the newspapers.
} 
to the material about the sea, the fish and the smacks. In addition, those readers meant that NNM focused too much on something nostalgic, on that Northern Norway which didn't exist.

Other kinds of criticism can also occur. For instance, it can deal with the editor's language usage in the editorials (Eriksen, 1981, p. 3) or his involvement in different cases, for example his standpoint against the Alta-extension (NNM, 1985, p. 16).

\section{The newspapers and their attitudes toward NNM}

As mentioned above, the majority of the readers were quite satisfied with NNM. Eriksen said then that those criticizing NNM did it in most cases in the newspapers. According to Eriksen, the magazine was criticized by some people for what it was, yet by others for what it wasn't (Eriksen, 1980 a, p. 3). Eriksen didn't clarify if these reactions applied to the newspapers in particular, or he thought of the readers' letters. I would like to investigate it further in this chapter.

Eriksen said that a lot of people thought that NNM was perhaps a stillborn enterprise when it started up. There were quite many warnings. The editorial staff met a lot of pessimists and sceptics who reminded them what had happened to Magazine forEveryone. In order to act from a position of strength there were also made attempts to beat hollow NNM straight away (Eriksen, 1979b, p. 3).

In NNM of 1982 (Eriksen, 1982, p. 3) Eriksen wrote the following starting his editorial in this issue:

Magazine is starting its fifth year. It wasn't supposed to be viable. Someone sentenced it to death at the start. Others tried to laud it to the skies. Some newspapers in the region tried to be completely silent. But Magazine was living further. It cost much to survive through four annual volumes, but we have had a reading group which all the time has given us support. Therefore it has gone well.

Which newspapers criticize NNM and who tries to understate the magazine?

In an article (Eriksen, 1980b) sent to me by Hans Kristian Eriksen he defines it more precisely. He said that he took the review in Northern 
Lights as mobbing, which was an attempt to make NNM stop as soon as possible. In a similar way he perceived also silence from some newspapers of the Labour party in Finnmark. It is exactly these newspapers he bears in mind when he speaks about total silence NNM was met by. According to Eriksen, they had never any news item about Magazine's appearance.

Eriksen indicates in the same article that there was also adverse criticism from some professionals. He asks a question if criticism or lack of reviews from special circles was an expression of disappointment that it was he who was responsible for the periodical, maybe others would have started?

If language is power, if what is read is accepted at face value and taken seriously, this criticism which the periodical gets, being good or bad, will be important for the magazine's acceptance by the majority of people. In other words, criticism will be important for the magazine's further existence.

Thus, Eriksen claims that Magazine has been stigmatized by special circles, especially some press circles, in the hope of stopping the enterprise as soon as possible. If his perception is correct it will be interesting to know why a large group of readers has loyally supported Magazine. But is it actually true that Eriksen's understanding and interpretation at all points coincide with the actual conditions?

\section{Recepton to Northern Lights, northern norways's largest newspaper}

From 1978 to 1988 the newspaper Northern Lights had eleven articles/ press releases/interviews in connection with NNM. The first article was written by the journalist Odd A. Sønvisen (Northern Lights, 1978, 11.5). Sønvisen wasn't filled with enthusiasm concerning NNM. The periodical was predicted a short lifetime. He was also sceptic to the fact that so many amateurs got access to the magazine.

Sønvisen's main objection was that NNM in its first issue appeared with a kind of contemplating the past, nostalgic tendency, old days were glorified. There were a lot of fine texts and pictures about the village, the fjord, the smack, the mountains and especially the sea, but it was difficult for Sønvisen to trace the fact that the region also had more than two hun- 
dred years old urban culture. He missed modern problems which people in Northern Norway also struggled with: traffic problems, medication abuse, drugs, loneliness etc.

Thus, Sønvisen and Northern Lights question in particular the editorial profile of NNM, the decentralized profile, and a great element of amateurs. The topic choice is criticized for being too narrow. Sønvisen demonstrates a controversial and ironic attitude when he interprets that NNM will «try to preserve Senja dialect as its own written form». Before the article had been written, he was informed about NNM's intentions in a conversation with Hans Kristian Eriksen.

Northern Lights continued being more critical towards NNM during the first years compared to other newspapers of that time. In an interview with Hans Kristian Eriksen to Northern Lights in 1980 (Northern Lights, 1980) some of Sønvisen's critical views were repeated as questions. The interviewer referred also to another kind of criticism which lay in the fact that NNM was too romantic and contemplating the past as the magazine had pictures of nature on most pages, quite a lot of history-oriented articles and nature descriptions ${ }^{2}$.

In later statements about NNM Northern Lights informs for the most part only of NNM's contents and gives generally a sympathetic description of the periodical. In 1987 Northern Lights (Northern Lights, 1978) published a positive article/interview by and with Hans Kristian Eriksen in connection with the tenth anniversary. NNM was described as a vigorous ten-year-old. The critical tone almost became silent.

What can the reasons be?

It is difficult to say for sure, but here I would like to present two possible explanations. Firstly, the critical comments in Northern Lights about NNM were mainly from Sønvisen. Since then he hasn't had similar articles in the newspaper where he has attempted to evaluate NNM's further development. Neither have other people in the newspaper done that. Secondly, NNM which constantly created its image in mass media

2 In a reader's letter (Out of the Writer Team. Reader's letter, 7.9) in Northern Lights (1978) Øyvind R. Jensen characterizes NNM as a «national- romantic foul-up». Its layout looks like - according to Jensen - a booklet published by a small North-Norwegian travel agency designed for rich North Americans. 
was perhaps gradually accepted - if not admired - as a part of NorthNorwegian cultural life.

\section{Finnmark Daily and Finnmarken}

Newspapers of the Labour party in Finnmark had in the beginning short paragraphs about Magazine. Finnmark Daily Paper (Finnmark Daily Magazine, 1978b, 11.10.) and Finnmarken (Finnmarken, 1978, 12.10) informed in October of 1978 that NNM was behind schedule with its fourth issue. In the autumn of 1978 Finnmark Daily Paper was able to inform that NNM published a new issue, and the periodical contained in particular highclass short stories (Finnmark Daily Magazine, 1978a, 18.10).

These two papers haven't written anything about NNM for more than a year and a half. Finnmark Daily Paper (Finnmark Daily Magazine, 1980, 30.7) and Finnmarken (Finnmarken, 1980, 4.8) informed in 1980 about NNM'S third issue that year. These were press releases sent by NNM.

Can one based on this say that NNM was kept silent about and ignored by these papers? We see that they wrote something.

\section{Was it newspapers that produced their own material and wrote more often about NM?}

Were there some newspapers in the region which produced their own material and made use of more space than others to inform about NNM?

Some newspapers informed more often and had longer and more self-produced articles about NNM and the editor. Rana Magazine, Troms Folk Magazine and Forward distinguished themselves in such a way. But also Harstad News, Tromsø, New Troms and Helgeland Worker's Magazine had some self-produced articles and/ or long announcements.

\section{How do north-norwegian newspapers receive NNM?}

The basic tone of the articles in North-Norwegian newspapers was positive. The majority of articles, self-produced or paraphrased press releases, in most cases informed about the contents of a specific issue of NNM and usually used positive adjectives in their descriptions, such as, for instance, 
«excellent vacation-reading» (Nordland's Post, 1980, 4.6), «versatile material» (Vesterålen, 1980, 9.8), «comprehensive and wide-ranging» (Tromsø, 1986, 18.12).

Here within the framework of the monograph I can only consider two such positive articles written by North-Norwegian press. However, they are in many ways typical examples of benevolence North-Norwegian newspapers met NNM by.

Stein Arve Myrbakk in Rana Magazine $(1980,19.12)$ commented on Christmas issue of that year and expressed his thoughts about NNM. He said that NNM was a capable of living magazine with a profile directed towards broad groups of readers, first of all in Northern Norway. Myrbakk stated that Magazine gave space to its own writers, and although he meant that not everything was fine, he thought that Eriksen with this material managed to reach out to the reader, especially because the editor wasn't afraid to accept the material dealing with those regional problems watchful people were engaged in in their everyday life.

Another article I would like to refer to is written by Finn Stenstad in Forward $(1987,14.4)$. In the article he asked in particular what NNM was really committed to and how people evaluated the magazine. He gave also an answer: NNM was first and foremost a spokesman for the broad cultural concept; the dividing lines between the professional and the original «folk» were never marked. He meant that a local cultural utterance in NNM was as valuable as a highly-cultured urban utterance. Belonging and identity in the periodical were - according to Stenstad central value concepts within all cultural activities; the roots, tradition and identity were keywords which had a resonator in all the prevenient annual volumes. It meant - according to him - that both the smack and the landing place, the fish on the drying rack and the farmer at the ploughtail could be found here, often side by side with the trawl and oil, power stations and industry.

Stenstad claimed that there was consistence and development all the time - backward and forward. He meant that it was the reason for critical voices to claim at times that NNM concentrated too much on the nostalgic, on the past of the northerner. He said that Eriksen was absolutely right when he answered the critics that without the past we didn't have the future. 


\section{How south norwegian newspapers receive NNM?}

Our Magazine $(1978,23.8)$ is the first newspaper outside the region writing about NNM. Eriksen is depicted as a man who started uniting Northern Norway into one cultural realm - or maybe more - North-Norwegian population into one nation.

«Excellent NNM», wrote Arne Skouen about Magazine in Daily Magazine $(1979,15.10)$, and Ulf Renberg claimed in Worker's Magazine (1980, 11.8) that NNM with its 11000 copies had become a part of North-Norwegian cultural image.

Øystein Hagen in Class Struggle (1980c, 13.11) characterized NNM as a daring magazine enterprise aiming at following in footsteps of Worker's Magazine, but with the material geographically limited to North-Norwegian cultural life. And later that year the newspaper wrote (1980a, 23.12) that NNM had to a great extent managed to achieve the aim of being the region's version of Worker's Magazine with similarly large circle of readers and access to the material which Worker's Magazine had in its golden era, and with increasing circulation.

Jan Nyberg wrote in Day and Time $(1982,30.9)$ that NNM was a concept and an institution in North-Norwegian region. He said that there was no lack of criticism against the magazine throughout the years, but that tension the criticism had created made the magazine become what it was that day: A well-edited, attractive forum for a broad group of people good at writing in the region. He wrote further that NNM reflected the broad cultural life of the region with an emphasis on the domestic, and it made visible aspects of North-Norwegian cultural life which otherwise hadn't appeared in already existing cultural forums.

Sverre M. Nyrønning compared in Advertiser $(1985,22.1)$ based in Trøndelag the periodical Arena with NNM. This comparison is real in the sense that none of the periodicals has support from a financially strong publisher. Nyrønning said that the result of such a comparison led to that Arena was brutally defeated. According to Nyrønning (Advertiser, 1985, 16.4), NNM had much of what Arena lacked, humour, good writers and detailed interviews with interesting people in the cultural sphere. NNM knew what resonator it would prioritize, where its market lay - without being intrusively provincial. 


\section{A comparison between NNM and Swedish sister magasines}

Following up upon the comparison above, I would like to explain shortly how a Swedish literature reviewer evaluates NNM compared to other periodicals in the North Calotte.

In Norrlandish Social Democrat $(1985,12.01 .85)$ Kent Lidman compared NNM to the periodicals Thule, Province and Hjärnestrøm. He claimed that NNM was most interesting in the North Calotte with high quality and coverage. He emphasized that in Magazine there were newly written prose and lyrics, polemic articles and relevant reportages. NNM had high-quality colour pictures, but Lidman missed thought-through editing. Moreover, he said that unfortunately the editorial staff didn't spend enough time on giving the pages a more attractive design (Norrlandish Social Democrat, 1985, 28.03.85).

\section{Different views of NNM}

If we take a look at reception in those articles I have referred to, it is clear that different newspapers evaluate NNM based on different approaches and contexts.

Sønvisen in Northern Lights proceeds from that NNM is supposed to reflect the whole North-Norwegian society and indicates that the periodical has a too narrow choice of topics, quite few «modern» problems.

Myrbakk in Rana Magazine claims that NNM is oriented towards broad groups of readers and accepts the material which is based on the region's own premises without making it more specific to a greater extent. It seems that Finn Stenstad in Forward agrees on it and means that the choice of topics in NNM is both comprehensive and wide-ranging.

The positive reviews of Class Struggle are to a great extent connected with the fact that it proceeds from the periodical's aim to follow in the footsteps of Worker's Magazine, and the newspaper claims that NNM has to a great extent succeeded in it.

Day and Time takes it for granted that NNM is a mirror for the whole cultural life of the region and that the periodical in one way or another has taken into «account» the received criticism, thus having become better. 
Advertiser and Norrlandish Social Democrat express positive comments about NNM by comparing Magazine in particular with other periodicals.

\section{Rounding and conclusion}

As we see, an overwhelming part of North-Norwegian press was positive towards NNM. Northern Lights was critical towards Magazine in the beginning, turned gradually over, and was friendly towards NNM at its tenth anniversary.

In this ten-year period I have registered 4-5 readers' letters expressing dissatisfaction with NNM, a small amount over such a relatively long period. On the other hand, it doesn't necessarily express that the majority of culture-interested people in the region were so enthusiastic. It is apparently first and foremost those engaged readers, positive or negative, who send in readers' letters. One can't draw conclusions based on investigation of the readers' letters about chilliness among the majority of people towards an enterprise, such as, for instance, NNM.

Above I have given some examples of attitude and approach expressed in South-Norwegian press about NNM and in a Swedish newspaper. Apart from Norrlandish Social Democrat which missed a more thought-through editing of NNM, I haven't found some other critical comments concerning NNM in the whole study material from the newspapers.

The newspapers conclude - in their particular manner - that it was a wise focus on the part of the editor which has led to NNM having high circulation - where a lot of periodicals have great problems with keeping it going, where others have succumbed.

Thus, there is a myth that there were many attempts to criticize or even beat hollow NNM in newspapers. This is shown by my newspaper study. The newspapers spread this myth which was produced by Eriksen and the editorial staff. At NNM's tenth anniversary this assertion was printed in the majority of Norwegian newspapers which had notification about the periodical.

Did Eriksen and the editorial staff of NNM want to exaggerate, after all, slight criticism against the periodical? Did the editorial staff try to draw a heroic picture of itself - the editorial staff which in spite of «opposition» from different circles succeeded in publishing a magazine beyond 
expectations? Or was it - anyhow until the beginning of the 1980s - that the writers' self-confidence was still so low in the region that one was hypersensitive even towards the most constructive criticism?

A partial answer to the last question can be connected with the fact that reviews of North-Norwegian books in North-Norwegian press at the beginning of the 1980s were unnecessary negative. Some book reviews, for instance, in Northern Lights, at the beginning of the 1980s were of such a category (Northern Lights, 1983, 5.5). It seemed that in some cases the reviewers followed Walter Benjamin's words: «Only that (critic) who can destroy can criticize» ${ }^{3}$. In that period there was not much contact between North-Norwegian writers and critics/book reviewers in North-Norwegian newspapers. In such a situation it is easy to assign dishonest motives to each other.

\section{References}

Advertiser (1985), Article. Norwegian newspaper.

Class Struggle (1980a), Article. Norwegian newspaper.

Class Struggle (1980b), North-Norwegian Magazine: Lives, flourishes and expands!

Interview. Norwegian newspaper.

Class Struggle (1980c), Without a title. Article. Norwegian newspaper.

Daily Magazine (1979), The scope. Chronicle. Norwegian newspaper.

Day and Time (1982), No regrets about folk culture. Article. Norwegian newspaper.

Eriksen Hans Kristian (1978), A late North-Norwegian spring. NNM, editorial, issue $2 / 78$.

Eriksen Hans Kristian (1979a), NNM, editorial, issue 4/79.

Eriksen Hans Kristian (1979b), NNM, editorial, issue 5/79.

Eriksen Hans Kristian (1980a), North-Norwegian literature and a world of weapon. NNM, editorial, issue 6/80.

Eriksen Hans Kristian (1980b), About NNM, Article, unpublished.

Eriksen Hans Kristian (1981), Letters from a cultural wildman. NNM, editorial, issue $3 / 81$.

Eriksen Hans Kristian (1982), The fifth year. NNM, editorial, issue 1/82.

Finnmark Daily Magazine (1978a), Headline. North Norwegian newspaper.

${ }^{3}$ Walter Benjamin's thirteen theses about criticism technique are in: W.B.: Einbahnstraße, Suhrkamp Verlag, Frankfurt/M. 1962, pp. 51-52. 
Finnmark Daily Magazine (1978b), NNM is late. Article, North Norwegian newspaper.

Finnmark Daily Magazine (1980), NNM moves further. Press release. North Norwegian newspaper.

Finnmarken (1978), North-Norwegian Magazine. Article. North Norwegian newspaper

Finnmarken (1980), NNM moves further. Press release. North Norwegian newspaper.

Forward (1987), Article. North Norwegian newspaper.

Larsen Roald (2012), North-Norwegian Magazine. An impulse sender and mirror of North-Norwegian cultural life. A monograph. Wydawnictwo Adam Marszalek, Toruń.

Larsen Roald (2017), North-Norwegian Magazine. The Editorial Staff, sister periodicals an reception. Scientific monograph. Wydawnictwo Adam Marszalek, Toruń.

NNM (1985), Readers' letters, issue 1/85.

Nordland's Post (1980), NNM moves further. Press release. North Norwegian newspaper.

Norrlandish Social Democrat (1985), Article. North Swedish newspaper.

Northern Lights (1978), Do we need North-Norwegian Magazine? Article. North Norwegian newspaper.

Northern Lights (1980), Interview with Hans Kristian Eriksen. North Norwegian newspaper.

Northern Lights (1983), Review by Sandvik. North Norwegian newspaper.

Northern Lights (1987), Article/interview with Hans Kristian Eriksen. North Norwegian newspaper.

Our Magazine (1978), Will unite Northern Norway into one realm. Interview with Hans Kristian Eriksen. Norwegian newspaper.

Rana Magazine (1980), Reading matter in Christmas season. Article. North Norwegian newspaper.

Tromsø (1986), North-Norwegian Christmas. Article. North Norwegian newspaper. Vesterålen (1980), NNM moves further. Press release. North Norwegian newspaper.

Walter Benjamin (1962), Thirteen theses about criticism technique. W.B.: Einbahnstraße, Suhrkamp Verlag, Frankfurt/M.

Worker's Magazine (1980), Article. Norwegian newspaper. 